\title{
In-Situ Transformation of Amorphous Soot into Carbon-Nanostructures by High- Energy Ball Milling
}

\author{
I. Estrada-Guel ${ }^{1,2}$, O. Anderson-Okonkwo ${ }^{1}$, F.C. Robles-Hernandez ${ }^{1}$ \\ 1. Department of Mechanical Engineering Technology, University of Houston, Houston, TX, USA. \\ 2. Centro de Investigación en Materiales Avanzados (CIMAV). Laboratorio Nacional de Nanotecnología \\ Miguel de Cervantes No. 120, 31109, Chihuahua, Chih., México.
}

Carbon structures can be bonded together in diverse ways forming several allotropes, known as graphite, diamond and amorphous carbon, where the properties each material varies widely. On the other hand, carbon nanostructures (allotropes at nanoscale) have been extensively researched for potential applications. Carbon nanostructures were extended to its application in energy related applications leading to the development of different carbon-based nanostructures with different shapes and sizes [1]. Of all the above-mentioned, graphene is more interesting, since its applications have reached out due to its unique properties: thermal, optical, electrical, mechanical, etc. [2]. Generally, carbon nanoreinforcements are used to improve mechanical properties ensuring the integrity of prepared composite [3]. Due to the high demand on carbon and carbon nanostructures, it is a technological challenge to get a cheap methodology to obtain these materials commercially.

The idea of the present work is the transformation (in-situ) of an amorphous material into complex carbon nanostructures using high-energy ball milling, obtaining a product with exceptional mechanical properties for structural applications as reinforcement. The raw material (a byproduct of the synthesis of fullerene) is abundant and does not have applications in the present. Fullerene soot was milled using a SPEX 8000M for 4h. After milling, samples were characterized via SEM in a JSM-7201F and TEM with a JEM2200-FS microscope. The Raman spectroscopy was conducted using a Horiba XploRA instrument with lasers of 638 and $532 \mathrm{~nm}$.

The figure 1 shows the un-milled soot in form of scattered carbon particles in a wooly form as a result of the evaporation process, forming agglomerates due Van Der Waals attraction (a). After milling (b) milling, the particle morphology exhibits significant changes from rounded to irregular with the presence of aggregates formed, at the expense of small crushed particles, by high-energy impact of milling media and powder.

In Fig. 2a a Raman spectrum is presented that shows the soot has a carbon-base nature due the presence of $\mathrm{D}$ and $\mathrm{G}$ band. The $\mathrm{D}$ band indicates the presence of defects, typical of a nanostructured carbon-based material. The 2D band is weak denoting that the carbon material has a high density of defects. After $4 \mathrm{~h}$ of milling, bands D and G increase in intensity; this is an evidence of the in situ formation of ordered carbon structures such as graphene and graphitic carbon. But the high intensity of the D band suggests high density of defects, and hence nanostructured particles. The 2D band indicated formation of graphenes from graphitic carbon that was fractured. Fig. $2 \mathrm{~b}$ shows a TEM image $4 \mathrm{~h}$ milled soot; here the presence of ordered carbon structures (graphene and graphitic carbon) is observable. As was previously discussed these phases are not crystalline due their high density of defects and nanocrystalline size.

References:

[1] N. Martin, D.M. Guldi and A. Hirsch, Energy Environ. Sci. 4 (2011), p. 604. 
[2] J.H. Warner et al., Graphene: Fundamentals to Applications, Elsevier (2012), 978-0-12-394593-8.

[3] E.S. Kim, G. Hwang, M. Gamal, Y. Liu, J. Memb. Sci. 394-395 (2012), p. 37-48.

[4] This research was supported by CONACYT (Project 169262) and the Redes Temáticas de Nanociencias y Nanotecnología (124886).
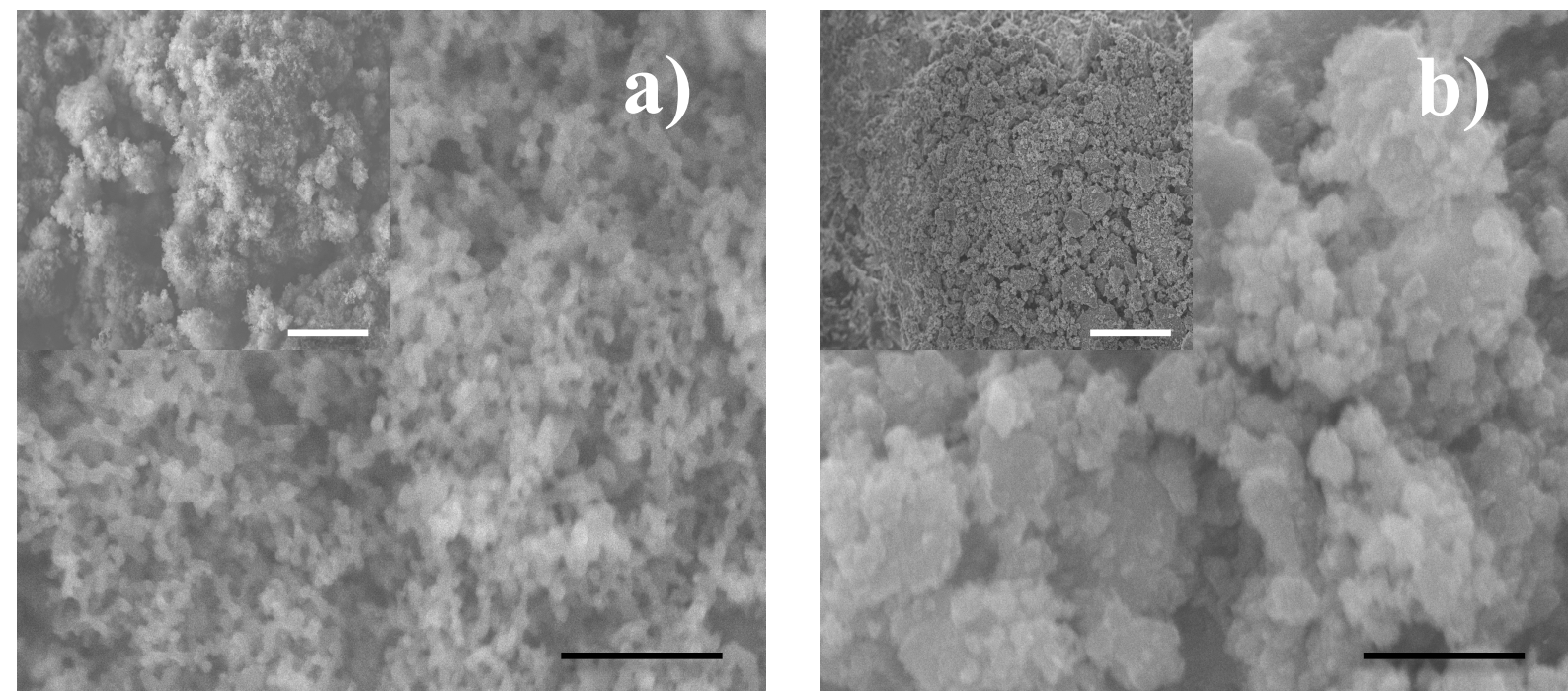

Figure 1. SEM micrographs of soot samples a) 0 and b) $8 \mathrm{~h}$ of milling $($ Black bars $=500 \mathrm{~nm}$, White bars $=250 \mu \mathrm{m})$.
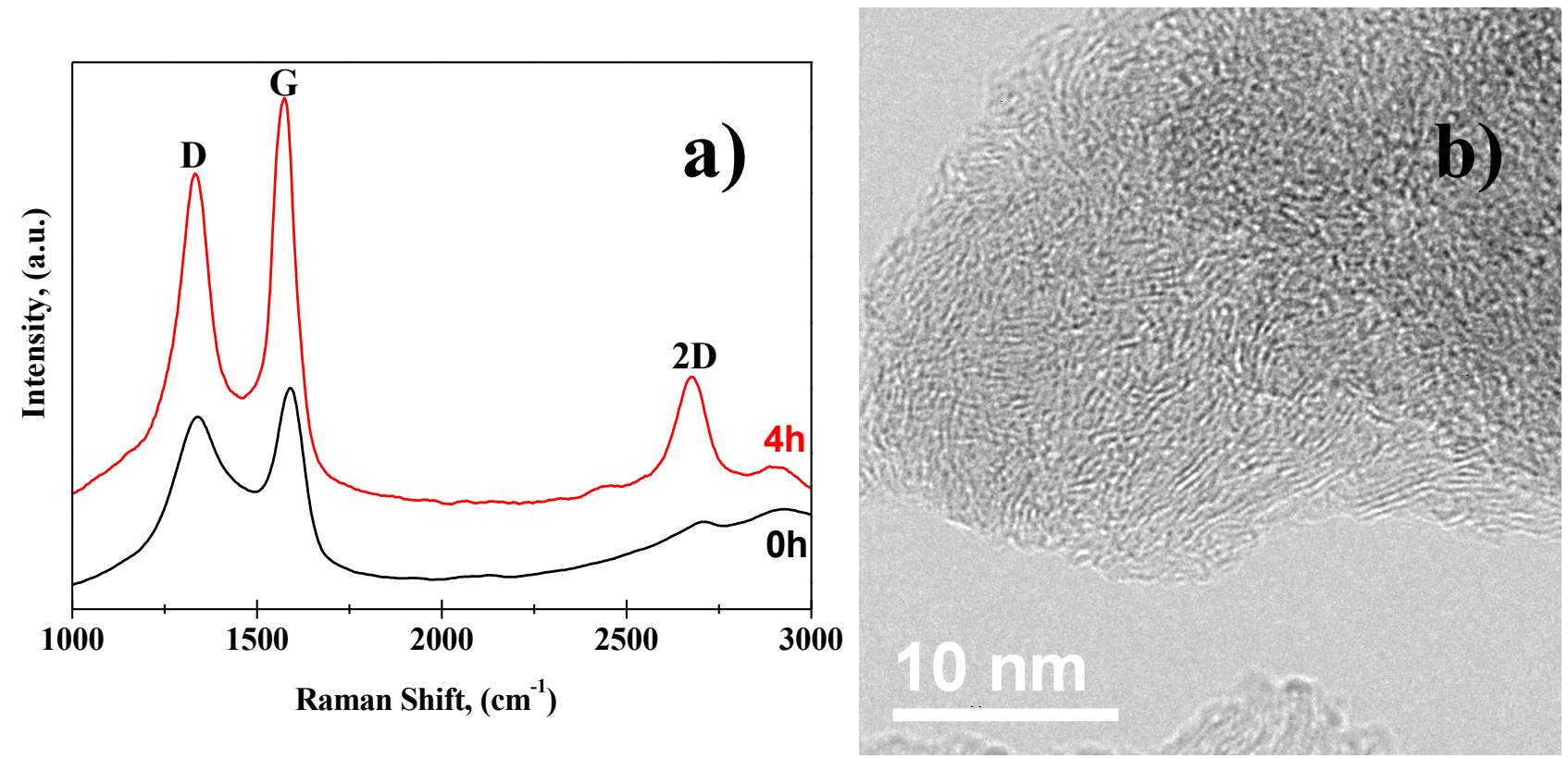

Figure 2. a) Raman spectra of soot samples identifying carbon bands, b) HREM image of a soot particle. 